ISSN: 2224-0616

Int. J. Agril. Res. Innov. \& Tech. 1(1\&2): 69-72, December, 2011

Available at http:// www.ijarit.webs.com

\title{
STUDY OF SHOOT MULTIPLICATION OF STRAWBERRY (Fragaria ananassa)
}

\author{
Nayem Zobayer, Shamsul H. Prodhan, Saif U. Sikdar, \\ Fazle Azim and M. Ashrafuzzaman*
}

Received 1 November 2011, Revised 23 December 2011, Accepted 25 December 2011, Published online 31 December 2011

\begin{abstract}
Effects of different hormonal concentration on multiple shoot formation of RABI Strawberry-3 were studied. Where the explants were runner tips that cultured on MS basal medium supplemented with 6-Benzyl Adenine and Kinetin. The maximum percentage $80 \%$ of shoot was obtained from Benzyl Adenine concentrations of $0.5 \mathrm{mg} / \mathrm{l}$ and $1.0 \mathrm{mg} / \mathrm{l}$ whereas Kinetin concentrations were $1.5 \mathrm{mg} / \mathrm{l}$ and $2.0 \mathrm{mg} / \mathrm{l}$ separately. More promising result was found by combining two impressive concentrations of each hormone. When MS basal media was supplemented with Kinetin 2.0mg/l + Benzyl Adenin A 0.5 mg/l, Kinetin 1.5 mg/l + Benzyl Adenine $0.5 \mathrm{mg} / \mathrm{l}$ and Kinetin $1.5 \mathrm{mg} / \mathrm{l}+$ Benzyl Adenine $1.0 \mathrm{mg} / \mathrm{l}$ respectively then $100 \%$ shoots were obtained.
\end{abstract}

Key words: RABI Strawberry-3, Benzyl Adenine, Kinetin, Shoot Formation and Regeneration

Department of Genetic Engineering \& Biotechnology, Shahjalal University of Science \& Technology, Sylhet, Bangladesh

*Corresponding author's email: azamanbt@gmail.com

Reviewed by Mahamud Hossain Al Mamun, Bangladesh Agricultural Reseasrch Institute, Bangladesh

\section{Introduction}

Strawberry (Fragaria ananassa) is a perennial, stoloniferous herb belongs to the family Rosaceae, genus Fragaria which is closely related to the genera include Duchesnea, the mock strawberry, Potentilla and the cinequefoils. Fragaria species have nine diploids, two tetraploids, one hexaploid, and four octoploids. Diploids $(2 \mathrm{n}=14)$ include F. vesca Duch., F. viridis Duch., F. nilgerrensis Schlect., F. daltoniana. J. Gray, F. nubicola Lindl. Ex Lacaita., F. iinumae Makino, F. yezoensis Hara, F. nipponica Makino, and F. mandschurica (Staudt, 1989). Among the many positive characteristics, the nutritional values of strawberries are nearly perfect. Eight medium strawberries contain more vitamin C than an orange (Driscoll, 2004).

It is also the most widely consumed fruits throughout the world. Strawberry is a rich source of phytochemicals (plant chemicals) of which phenolic compounds predominate. Berry fruits are reported to contain a wide variety of phenolics including hydroxybenzoic and hydroxycinnamic acid derivatives, anthocyanins, flavonols, condensed tannins (proanthocyanidins) and hydrolyzable tannins (Machiex et al., 1990). Studies conducted in vitro indicate that berry phenolics have a wide range of biological properties such as anti-cancer, antioxidant, antiinflammatory and cell regulatory effects (Seeram, 2006a; Seeram and Heber, 2006b).
The micropropagation of strawberry was achieved more than 30 years ago (Boxis, 1999) and now it seems to be a routine task in many commercial laboratories. In general, strawberry can be managed easily under in vitro conditions. Meristem tips, generally obtained from runners of virus-free plants are commonly used to establish in vitro cultures which are employed for mass propagation or as a source of plant material for regeneration and transformation experiments (Mercado et al., 2007). Numerous studies have been published regarding field behavior of micropropagated strawberry. Several parameters used during the in vitro phase that can affect the behavior of micropropagated strawberry in the nursery, e.g. plant genotype, mineral formulation, type and concentration of cytokinin in the medium and the number of subcultures. It is generally recommended not to exceed four to five subcultures to avoid loss of trueness-to type of the propagated material (Faedi et al., 2002). This technique is useful in case of the introduction of new cultivars. Moreover, the storage of tissue cultured propagules requires less space than traditional runner plant and the in vitro storage can be initiated at any time during the production cycle (Swartz et al., 1981). Prior experiences with strawberry micropropagation indicate that invitro plants are more uniform, produce higher number of runners, have better survival in the field, and the fruit yield increases in $24 \%$ than 
plants propagated by the traditional method (Kikas et al., 2006) .Thus, plant tissue culture techniques can be applied as an alternative for the traditional plant-breeding methods which are time consuming. By tissue culturing technique of Strawberry explants, there is a chance to establish unique cell lines of Strawberry or somaclonal varieties. Some authors have reported that frequent callus formation as an intermediary phase just prior to somatic embryogenesis or regeneration to protocorms (Tisserat and J ones, 1999; Ishii et al., 1998). Direct regeneration without undesirable callus formation shortens the time period needed for regeneration and reduces the possibility of the occurrence of somaclonal variability (Kosir et al., 2004). The present study was carried out an aim to study multiple shoot regeneration system from runner tips of RABI strawberry-3 for future many advanced biotechnological uses such as efficient and rapid micro-propagation and genetic transformation system in future.

\section{Materials and Methods}

This experiment was conducted in Plant Genetic Engineering Laboratory of Shahjalal University of Science and Technology, Sylhet-3114, Bangladesh. The details of the materials and methods in this experiment are given below.

\section{Explant materials}

Strawberry plantlets of RABI Strawberry-3 were collected from Rajshahi University. Healthy and vigorous runner tips were collected from the strawberry plants, which were used as explants. During transferring bud to solid sterile medium a whitish exudates of bacteria was observed around the base of the explants after 2-3 days and it was complicated further by the latent nature of the contaminants. The exudates were removed by placing the runner tips were placed in autoclaved beaker and washed with sterile distilled water. The runner tips were then kept in $70 \%$ of ethanol for 3-5 miniutes, followed by washing with autoclaved distilled water for several times. Runner tips were further sterilized by continuous shaking with adding Sodium hypochlorite with 23 drops of tween-20 for 12-15 minutes. Surface sterilized runner tips were thoroughly washed five times with autoclaved sterile distilled water. The runner tips were then placed on the sterilized petridishes having sterilized filter paper to remove excess water from the runner tips.

Media preparation and culture of explants

Runner tips were cultured on MS supplemented with specific concentration of growth regulators (BA and Kinetin) followed by the method by Emarah (2008). After surface sterilization apical meristems of 3-5 mm long were isolated and used as explants. Firstly, the growth regulators were supplemented in the media singly. Then, on the basis of performance two best concentrations were selected from each growth regulators. Surface sterilized runner tips were placed on solid MS media in a laminar airflow cabinet. In each test tube one runner tip was placed. The $\mathrm{pH}$ of the media was adjusted to $5.8 \pm 2$ before autoclaving. After inoculation, the surface sterilized runner tips of RABI Strawberry-3 variety was transferred and maintained in an environmentally controlled growth room for 3 weeks for multiple shoot generation and growth. The cultures were positioned away from continuous light provided by general electric white florescent tubes. Temperature was maintained at $25 \pm 2{ }^{\circ} \mathrm{C}$ through the growth period. Multiple shoot generation and growth frequency was recorded 12-15 days after inoculation. Subculture was carried out once in every two weeks with transfer of only the vigorously growing explants. Experiments were replicated three times and forty test tubes with forty runner tips were used per replication for each type.

Frequency of multiple shoot generation was calculated according to the following formula

Multiple shoot generation frequency (\%)

$$
=\frac{\text { No. of runner tipe produced multiple thoote }}{\text { No.of runner tips eultured }} \times 100
$$

\section{Result and Discussion}

From the study, a great number of multiple shoot were successfully obtained. MS basal media supplemented with KIN 2.0 mg/l + 1.0 BA mg/l was resulted $100 \%$ of shoot formation as well as supplemented with KIN $1.5 \mathrm{mg} / \mathrm{l}+$ BA $0.5 \mathrm{mg} / \mathrm{l}$ and KIN $1.5 \mathrm{mg} / \mathrm{l}+\mathrm{BA} 1.0 \mathrm{mg} / \mathrm{l}$. Whereas MS basal media provided with KIN $2.0 \mathrm{mg} / \mathrm{l}+\mathrm{BA}$ $0.5 \mathrm{mg} / \mathrm{l}$ showed $80 \%$ efficiency.

Addition of adequate levels of BA and Kinetin into a basal medium resulted in prolific multiple shoot generation. Results of the study reveled that multiple shoot generation of strawberry often proceeded on media containing the higher BA and lower kinetin concentrations but either of the lower BA and higher Kinetin concentrations, multiple shoot forms directly. Among the best five of each concentration 4, 4, 1 , 0 explants produced multiple shoots at $0.5,1$, 1.5, $2.0 \mathrm{mg} / \mathrm{l}$ BA respectively and 1, 2, 4, 4 for $0.5,1.0,1.5,2.0 \mathrm{mg} / \mathrm{l}$ Kinetin concentration respectively. By combining two impressive concentrations from each PGRs group 5, 5, 4, 5 explants produced multiple shoots at $2.0 \mathrm{KIN}+$ $0.5 \mathrm{BA} \mathrm{mg} / \mathrm{l}, 1.5 \mathrm{KIN}+0.5 \mathrm{BA} \mathrm{mg} / \mathrm{l}, 2.0 \mathrm{KIN}+$ $1.0 \mathrm{BA} \mathrm{mg} / \mathrm{l}, 1.5 \mathrm{KIN}+1.0 \mathrm{BA} \mathrm{mg} / \mathrm{l}$ respectively. 
Table 1. Effects of BA and KIN on Shoot Formation of RABI Strawberry-3

\begin{tabular}{lllll}
\hline Hormone & Concentration(mg/l) & \% Shoot formation & Observation & Shoot length(cm) \\
\hline \multirow{2}{*}{ BA } & 0.5 & $80 \%$ & +++ & $6 \pm 0.9$ \\
& 1.0 & $80 \%$ & +++ & $6 \pm 1.5$ \\
& 1.5 & $20 \%$ & + & $4 \pm 0.3$ \\
& 2.0 & $0 \%$ & - & 0 \\
KIN & 0.5 & $20 \%$ & + & $4 \pm 0.4$ \\
& 1.0 & $40 \%$ & ++ & $5 \pm 0.1$ \\
& 1.5 & $80 \%$ & +++ & $7 \pm 0.5$ \\
& 2.0 & $80 \%$ & +++ & $7 \pm 1.2$ \\
\hline
\end{tabular}

Here, No multiple shoot $=-$, Poor multiple shoot $=+$, Average multiple shoot $=++$, Good multiple shoot $=+++$, Very good multiple shoot $=++++$

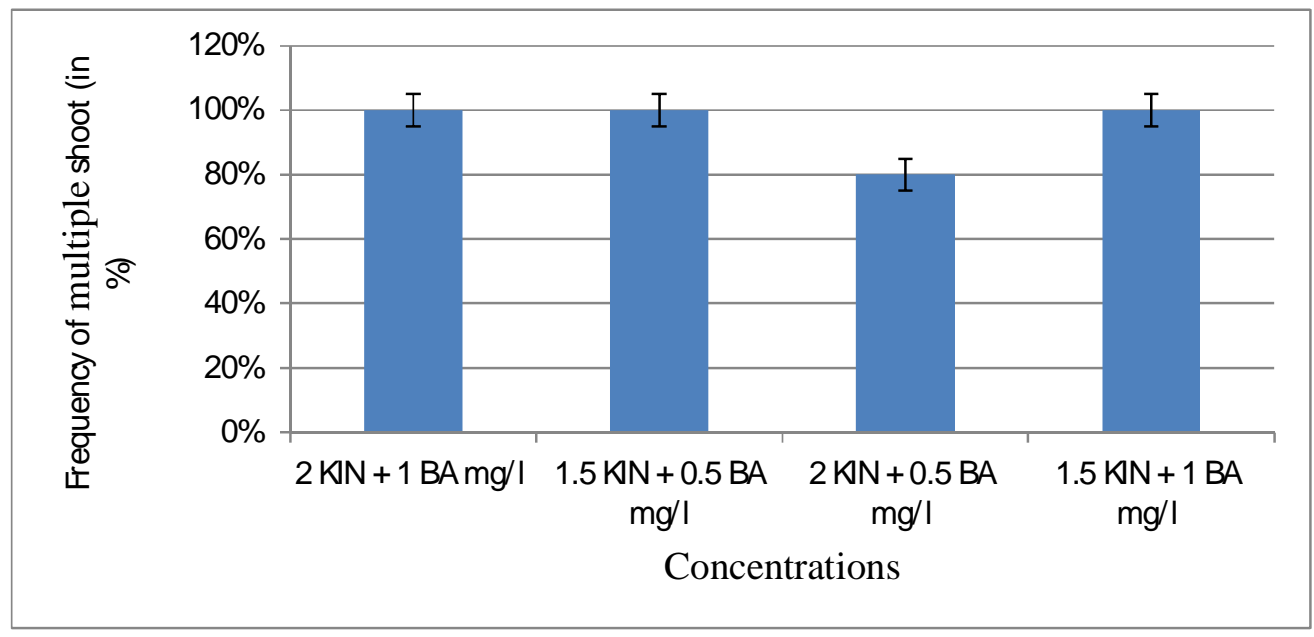

Fig. 1. Promising outcome in combination of two best concentration of BA and KIN

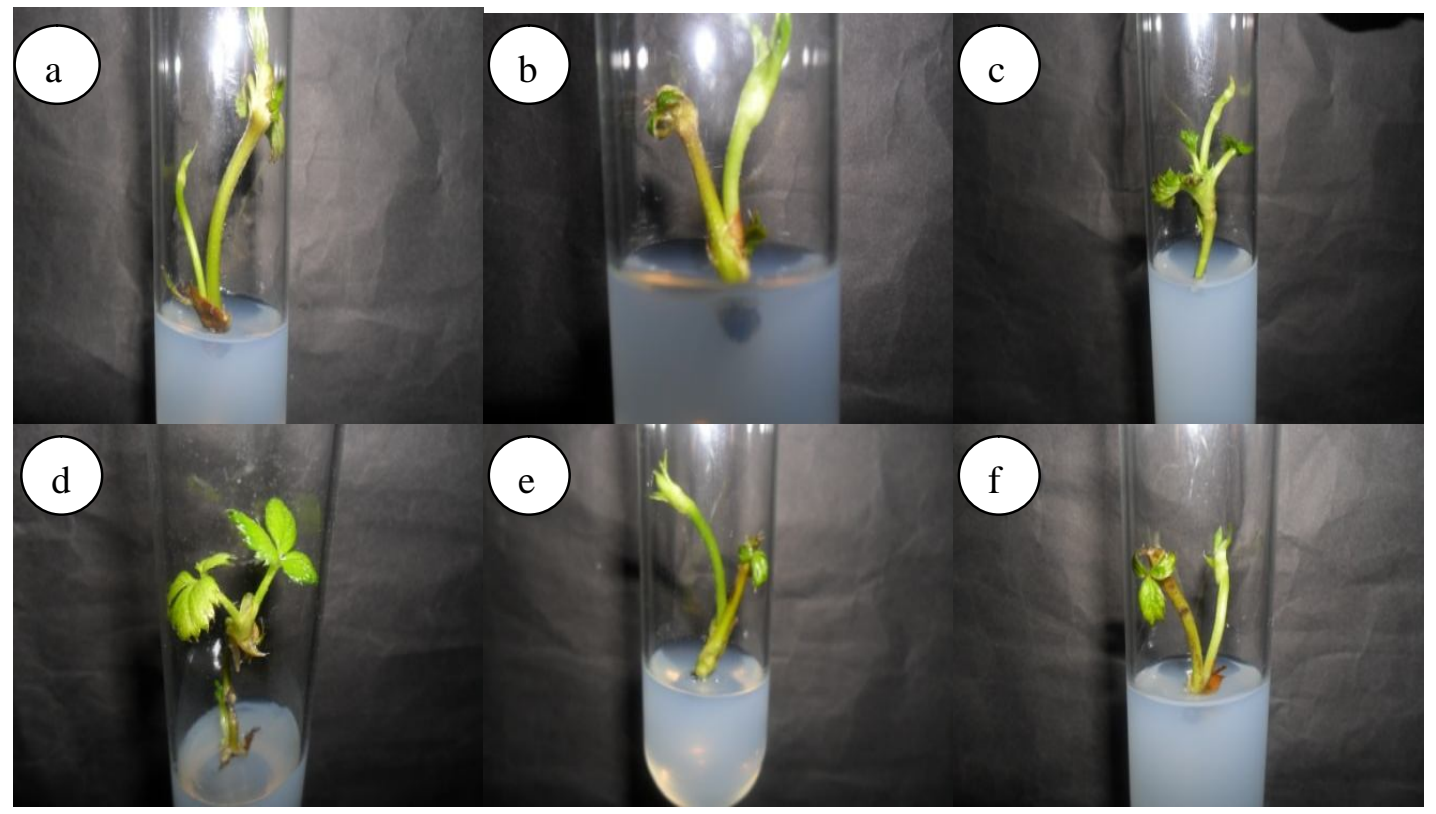

Fig. 2. (a) Shoot proliferation in MS media supplemented with $2.0 \mathrm{mg} / \mathrm{l} \mathrm{KIN}+0.5 \mathrm{BA} \mathrm{mg} / \mathrm{l}$; (b) \& (c) Shoot proliferation in MS media supplemented with $1.5 \mathrm{KIN} \mathrm{mg/l} \mathrm{+} 0.5 \mathrm{BA} \mathrm{mg} / \mathrm{l}$; (d) \& (e) Shoot proliferation in MS media supplemented with $2.0 \mathrm{mg} / \mathrm{l} \mathrm{KIN} \mathrm{+1.0} \mathrm{BA} \mathrm{mg/l;} \mathrm{(f)} \mathrm{Shoot} \mathrm{proliferation} \mathrm{in} \mathrm{MS} \mathrm{media} \mathrm{supplemented} \mathrm{with}$ $1.5 \mathrm{mg} / \mathrm{l} \mathrm{KIN} \mathrm{+} 1.0 \mathrm{BA}$ mg/l 
Effects of mineral salts, BA levels and the number of times and explant was subcultured on the regeneration capacity was observed in vitro culture of strawberry (Lopez-Aranda, et al., 1994). The field behavior of the regenerates was also tested in the comprehensive investigation. The proposed medium was supplemented with concentration of growth hormone BA $(0.5 \mathrm{mg} / \mathrm{l}$, $1.0 \mathrm{mg} / \mathrm{l}, 1.5 \mathrm{mg} / \mathrm{l}$ and $2.0 \mathrm{mg} / \mathrm{l})$ and KIN (0.5 $\mathrm{mg} / \mathrm{l}, 1.0 \mathrm{mg} / \mathrm{l}, 1.5 \mathrm{mg} / \mathrm{l}$ and $2.0 \mathrm{mg} / \mathrm{l})$. Sakila et al. (2007) showed that nodal segments of strawberry gave rise to multiple shoots when cultured on MS medium supplemented with different concentration of BA with KIN or GA3. The highest response of shoot multiplication was obtained in MS containing $1.5 \mathrm{mg} / \mathrm{l} \mathrm{BA}+0.5 \mathrm{mg} / \mathrm{l}$ KIN. The regenerated shoot lets were rooted on MS basal medium with different concentrations IBA and IAA. The maximum frequency of rooting and the highest number of roots was produced on medium containing $1.0 \mathrm{mg} / \mathrm{l}$ IBA. The plantlets, thus developed were hardened and successfully established in soil. The plants raised through tissue culture exhibited normal growth, flowering and fruit setting.

\section{Conclusion}

For multiple shoots formation, lowest concentrations of BA i.e., 0.5 and $1.0 \mathrm{mg} / \mathrm{l}$ were outstanding. Combination of high concentrations of KIN i.e., 2.0 and $1.5 \mathrm{mg} / \mathrm{l}$ with lower concentrations of BA resulted more effectively than the single cytokinin treatment. As strawberry is still a new crop in Bangladesh so more research should be carried on to further improvement of this crop.

\section{Acknowledgement}

We are thankful to the authority of National Museum of Science and Technology, Agargaon, Dhaka, Bangladesh for their financial support to carry out this study.

\section{References}

Boxis, P. 1999. Micropropagation of strawberry via axillary shoot proliferation. Plant Cell Culture Protocols. Methods in Molecular Biology. Part III. Plant Propagation In Vitro. Hall R.D. (ed.) Humana Press Inc., Totowa NJ. 111: 103-114.

Driscoll, S.2004.http:/ / www.driscolls.com/strawb erries/ nutrition.html.

Emarah. 2008. Factors affecting propagation of strawberry (Fragaria spp.) through tissue cultures. J . Product. \&Dev., 13 (1): 191-212.

Faedi, W., Mourgues, F. and Rosati, C. 2002. Strawberry breeding and varieties: situation and perspectives. Acta Horticulturae, 567: 51-59.
Kikas, A., Libek, A. and Vasar, V. 2006. Influence of micropropagation on the production of strawberry runner plants, yield and quality. Acta Horticulturae. 708: 241-244.

Lopez-Aranda, J.M., Pliegoalfaro, F., Lopeznavidad, I. and Barceló-munoz, M. 1994. Micropropagation of strawberry (Fragaria $\mathrm{x}$ ananassa-Duch). Effect of mineral salts, benzyladenine levels and number of subcultures on the in vitro and field behavior of the obtained microplants and the fruiting capacity of their progeny. $\mathrm{J}$. Hort. Sci., 69 (4):625-637.

Macheix, J.J., Fleuriet, A. and Billiot, J. 1990. Changes and metabolism of phenolic compounds in fruits, in Fruit Phenolics, ed. By Macheix, J.J ., Fleuriet, A. and Billiot, J . CRC Press, Boca Raton FL. pp. 149- 221.

Mercado, F., Pliego-Alfaro and Quesada, M.A. 2007. Strawberry. Transgenic Crops V, Biotechnology in Agriculture and Forestry, 60 (1): 309-328.

Sakila, S., Ahmed, M.B., Karim, R., Roy, U.K., Biswas, M.K., Karim, R., Razvy, M.A., Hossain, M.A., Islam R. and Hoque, A. 2007. Micropropagation of Strawberry (Fragaria X ananassa Duch.). A Newly Introduced Crop in Bangladesh. AmericanEurasian J. Sci. Res., 2(2): 151-154.

Seeram, N.P. 2006a. Berries, PP. 615-625. In: D. Heber et al. (eds). Nutritional Oncology, 2nd ed. Academic Press, London, UK.

Seeram, N.P., and Heber, D. 2006b. Impact of berry phytochemicals on human health: Effects beyond antioxidation. In: C.T. Ho et al. (Eds). Lipid oxidation and antioxidants: Chemistry, Methodologies and Health Effects. ACS Symposium Series. Oxford University Press.

Staudt, G., 1989. The species of Fragaria, the taxonomy and geographical distribution. Acta Horticulturae, 265:23-33.

Swartz, H.J., Galletta, G.J. and Zimmerman, R.H. 1981. Field performance and phenotypic stability of tissue culture propagated strawberries. J. Am. Soc. Hort. Sci., 106: 667-673.

Kosir, P., Skof, S. and Luthar, Z. 2004. Direct shoot regeneration from nodes of Phalaenopsis orchids. Acta agriculturae slovenica, 83(2): 233 - 242.

Tisserat, B. and Jones, D. 1999. Clonal propagation of orchids. In: Hall, R.D. (Ed.): Plant Cell Culture Protocols. Methods in Molecular Biology, 111. Humana Press Inc., Totowa, NJ , USA, pp. 127-134.

Ishii, Y., Takamura, T., Goi, M. and Tanaka, M. 1998. Callus induction and somatic embryogenesis of Phalaenopsis. Plant Cell Rep., 17: 446-450. 